\title{
Conjuntivite e COVID-19
}

Conjunctivitis and COVID-19

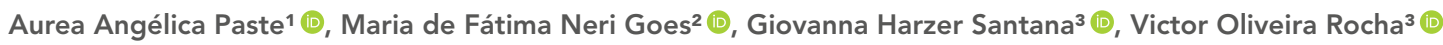

1 Universidade Federal da Bahia, Salvador, BA, Brasil. 2 Instituto de Cegos da Bahia, Salvador, BA, Brasil.

${ }^{3}$ Curso Acadêmico de Medicina, Universidade Federal da Bahia, Salvador, BA, Brasil; Liga de Infectologia da Bahia, Salvador, BA, Brasil.

\section{Descritores:}

Conjuntivite; Infecções por coronavirus; COVID-19.

SARS-CoV2

Keywords:

Conjunctivitis; Coronavirus infections; COVID-19;

SARS-CoV-2

Submetido: $5 / 7 / 2020$

Aceito:

25/3/2021

Autor correspondente: Nome Aurea Angelica Paste Endereço: R. Benjoim n. 71 apto 402, Caminho das Arvores, Salvador Bahia

E-mail: aureapaste@hotmail.com.br

Instituição de realização do trabalho: Universidade Federal da Bahia, Salvador, BA, Brasil.

Fonte de auxílio à pesquisa: não financiado.

Conflitos de interesse: os autores declaram que não há conflitos de interesses.

\section{RESUMO}

Apresentamos um caso de conjuntivite por SARS-CoV-2 em mulher de 55 anos, com hiperemia e sensação de corpo estranho em ambos os olhos. O exame oftalmológico revelou conjuntivite. A paciente apresentou reação em cadeia da polimerase de SARS-CoV-2 detectável em swab conjuntival e nasal. O tratamento foi realizado com colírio de ciprofloxacina, corticoide e trometamol por 5 dias. Após o sétimo dia de evolução, houve melhora importante da conjuntivite, e foi repetido swab conjuntival, com resultado não detectável.

\section{ABSTRACT}

We present a case of SARS-CoV-2 conjunctivitis in a 55-year-old female patient, with hyperemia and foreign body sensation in both eyes. The eye examination revealed conjunctivitis. She had detectable SARS-CoV-2 by polymerase chain reaction on conjunctival and nasal swabs. She was treated with ciprofloxacin eye drops, corticosteroids and trometamol for 5 days. After the seventh day of evolution, there was a significant improvement in conjunctivitis, and repeated conjunctival swab was negative. 


\section{INTRODUÇÃO}

A COVID-19 é causada pelo coronavírus da síndrome respiratória aguda grave 2 (SARS-CoV2), um novo vírus envelopado, RNA de fita única, zoonótico, da família Coronaviridae, filogeneticamente próximo ao coronavírus SARS-CoV, emergido em 2002..$^{(1,2)}$ Disseminou-se pela China, onde surgiu em 2019, e pelo mundo, atingindo rapidamente o status de pandemia, estando presente em cerca de 216 países, segundo dados da Organização Mundial da Saúde (OMS) de junho de 2020.(3) No Brasil, até o dia 23 de maio de 2020, 347.398 casos tinham sido confirmados. ${ }^{(4)}$

Desde os primeiros relatos na China, quadros graves, como síndrome respiratória aguda grave e pneumonia, já mostravam associação com a infecção pelo agente etiológico da doença. ${ }^{(2)}$ A maioria dos pacientes se mantém assintomática (80\%), enquanto cerca de 20\% dos infectados manifestam sintomas, podendo necessitar, nos casos mais graves (5\%), de suporte intensivo e ventilação mecânica. ${ }^{(1)}$

A transmissão ocorre principalmente pela via respiratória, por meio de gotículas contaminadas e pelo contato. Contudo, outras vias de propagação estão sendo investigadas, como as fezes, bem como o papel delas na transmissão.(1)

Os sintomas mais característicos da infecção pelo SARSCoV2 são os respiratórios, como tosse, febre, coriza, dor de garganta e dispneia. ${ }^{(1)}$ Eles costumam ser mais severos em pacientes com idade mais avançada, com comorbidades e/ ou doenças respiratórias. ${ }^{(2)}$ Manifestações em outras regiões do corpo estão sendo cada vez mais descritas, incluindo o trato gastrintestinal, o tecido nervoso e o tecido ocular. ${ }^{(5)}$

Alguns estudos preliminares já têm mostrado a conjuntivite como manifestação clínica importante, a qual acomete os pacientes sintomáticos numa taxa que pode chegar a 18\%. Em alguns desses sujeitos, fragmentos de RNA viral puderam ser detectado nas lágrimas. ${ }^{(6)}$ Mais estudos sobre essas manifestações atípicas são de grande importância, não apenas para que possam ser manejadas da melhor forma, mas também pela possibilidade de sinalizarem outras vias de transmissão. ${ }^{(5)}$

Dessa forma, objetivamos relatar um caso de conjuntivite por SARS-CoV-2 em mulher de 55 anos, com hiperemia e sensação de corpo estranho em ambos os olhos.

\section{RELATO DE CASO}

Paciente do sexo feminino, 55 anos, branca, sem comorbidades, previamente hígida, procurou oftalmologista, pois, no dia $1^{\circ}$ de junho de 2020 , iniciou hiperemia, sensação de corpo estranho e discreta secreção amarelada em olho direito. Negava tosse, odinofagia, mialgia, cefaleia, anosmia ou qualquer outro sintoma. Iniciou no mesmo dia colírio de ciprofloxacina.

No dia seguinte, apresentou piora em olho direito e iniciou os mesmos sintomas em olho esquerdo, sem sintomas sistêmicos. Foi novamente avaliada por oftalmologista, que encontrou acuidade visual em ambos os olhos 20/20 com correção. No olho direito, estavam presentes inúmeros folículos, pequena quantidade de papilas e secreção mucoide, hiperemia conjuntival e quemose; estavam ausentes membranas e hemorragia subconjuntival; a córnea não apresentava alteração. No olho esquerdo, estavam presentes folículos e discreta hiperemia. A córnea não tinha alterações. Foi medicada com colírios: fluormetolona, trometamol e ciprofloxacina. Evoluiu sem sintomas sistêmicos, exceto astenia moderada.

No dia 4 de junho de 2020, coleta de transcrição reversa seguida de reação em cadeia da polimerase detectou SARS-CoV2 nasal e em esfregaço conjuntival. Foi mantida a conduta pela oftalmologia.

Em reavaliação em 9 de junho de 2020 verificou melhora importante da hiperemia e da sensação de corpo estranho nos olhos. No olho direito, observaram-se presença de folículos e melhora da quemose e da hiperemia conjuntival (Figura 1), além de ceratite discreta perilímbica. No olho esquerdo, estavam presentes folículos e ceratite discreta perilímbica.

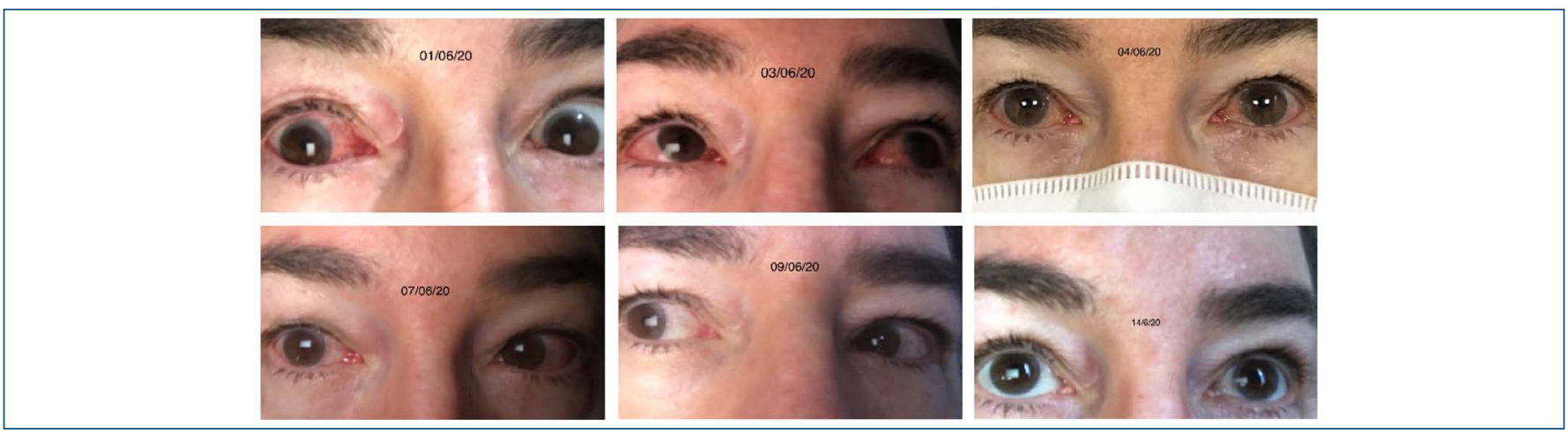

Figura 1. Evolução da hiperemia conjuntival à direita e, depois, bilateral, com posterior melhora. 
Ainda no sétimo dia de evolução (9 de junho de 2020), foi repetido esfregaço conjuntival em ambos os olhos com resultado não detectado. Demais exames coletados tiveram os seguintes resultados: hemoglobina em 13,5 g/dl; hematócritos 40\%; leucócitos 6.900 $\mathrm{U} / \mu \mathrm{L}$; bastonetes $\mathrm{O} \%$; segmentados $54 \%$; eosinófilos 3\%; linfócitos 35\%; monócitos 8\%; plaqueta 312.000; dimero D 352 (<600); troponina <0,2 ng/ml (até 1,0 $\mathrm{ng} / \mathrm{ml})$; velocidade de hemossedimentação $11 \mathrm{~mm} / \mathrm{h}$; Razão Normalizada Internacional RNI 0,9; tempo de protrombina 123\%; fibrinogênio 316 mg/dl (200 a 400 $\mathrm{mg} / \mathrm{dl}$ ); ureia 28,6 mg/dl; creatinina 0,1 mg/dl; transaminase oxalacética 23,7 U/L; transaminase pirúvica 33 U/L; creatinofosfoquinase 48,4 U/L (<170 U/L); proteína C-reativa 1,4 mg/L (<5,0 mg/L); lipoproteína de alta densidade 196,8 mg/dl (240 a $480 \mathrm{mg} / \mathrm{dl}$ ); ferritina 105 (13 a $150 \mathrm{ng} / \mathrm{ml}$ ). Evoluiu com astenia e sem outros sintomas associados à COVID-19.

\section{DISCUSSÃO}

A diversidade de manifestações clínicas possíveis da COVID-19 representa um desafio para profissionais da saúde, principalmente em função da alta transmissibilidade do vírus SARS-CoV2 e da dificuldade de reconhecer o paciente infectado quando ele apresenta a forma leve da doença ou sinais e sintomas atípicos. ${ }^{(7)} \mathrm{Com}$ as evidências disponíveis na literatura, ainda não é possível determinar se o vírus apenas coloniza a estrutura ocular ou se está presente na lágrima, podendo fundamentar outra forma de transmissão da doença. ${ }^{(8)}$

Nesse contexto, reconhecer a conjuntivite como possível sintoma da COVID-19 é importante tanto para tratar o paciente de forma adequada, como também para guiar as recomendações de utilização de equipamentos de proteção individual dos profissionais da saúde. ${ }^{(7)}$ Poucos estudos foram realizados até o momento para tentar dimensionar a importância e a distribuição dessa manifestação, com pesquisas preliminares e de baixa amostragem mostrando taxa que varia de $2,8 \%$ a $18 \%$ de pacientes sintomáticos com conjuntivite. ${ }^{(6)}$ Dessa forma, é necessário incluir a COVID-19 no diagnóstico diferencial para pacientes que apresentam conjuntivite ou sinais oculares. Além disso, considerar os achados oculares no diagnóstico e no manejo da COVID-19 pode ser de grande relevância, já que evidências mostram possível relação entre a presença deles com uma resposta inflamatória mais agressiva no paciente. Foram observados maiores valores de proteína C-reativa, procalcitonina, lactato desidrogenase, contagem de neutrófilos e taxa de sedimentação dos eritrócitos nos pacientes com manifestações oculares, bem como contagem de linfócitos reduzida. $(9,10)$

Quanto à fisiopatologia para a inoculação viral na conjuntiva, as teorias propostas incluem inoculação direta da conjuntiva a partir de gotículas infectadas; migração da infecção do trato respiratório superior pelo ducto nasolacrimal; e infecção hematogênica da glândula lacrimal. (11) Tais hipóteses embasam-se na presença do receptor ACE2, essencial para a entrada do SARS-CoV2 nas células humanas, em diversas estruturas do olho humano, como córnea, conjuntiva, íris, corpo ciliar e humor aquoso. ${ }^{(12,13)}$

Com relação às manifestações clínicas, pacientes infectados com SARS-CoV2 podem apresentar sintomas de conjuntivite como manifestação inicial, ou em conjunto com demais sintomas sistêmicos graves, ou até mesmo como única manifestação da doença. ${ }^{(11,14)}$ Também há relatos de complicações oculares tardias (que ocorrem em período superior a 2 semanas do início da doença) em pacientes com COVID-19. ${ }^{(15)}$

Presume-se que as manifestações oculares da COVID-19 sejam autolimitadas e possam ser tratadas com cuidados sintomáticos. ${ }^{(11)}$ Na literatura analisada, o método de diagnóstico da conjuntivite nos pacientes com COVID-19 foi por meio dos achados clínicos característicos de conjuntivite aguda, como hiperemia conjuntival, sensação de corpo estranho, lacrimejamento, olho seco e fotofobia..$^{(6,1)}$

Com relação à investigação da presença de RNA viral na superfície ou em secreções oculares, os métodos de amostragem das secreções incluem swab conjuntival direto, as tiras do teste de Schirmer e micropipetas capilares de vidro. Já a base para detecção do vírus é a RT-PCR, a cultura viral ou o efeitos citopáticos (CPE). ${ }^{(16)}$ Uma revisão sistemática analisou 252 pacientes infectados por SARSCoV2 submetidos ao swab conjuntival: três pacientes apresentaram conjuntivite com PCR positivo para o swab; oito tiveram PCR positivo para o swab e não apresentaram conjuntivite e 14 tiveram conjuntivite com resultado negativo para o PCR conjuntival. ${ }^{(17)}$ Essa inconsistência, também presente em outros estudos, ${ }^{(13,18)}$ pode se dar pela baixa carga viral da secreção conjuntival ou pela coleta ou pelo manuseio inadequados das amostras.

Também existe a hipótese de que a conjuntivite, nesses pacientes, ocorra devido a uma reação sistêmica generalizada a uma infecção em outro local por SARSCoV2. ${ }^{\left({ }^{13)}\right.}$ Apesar de a possibilidade de transmissão viral pelas lágrimas ainda não estar bem definida, a American Academy of Ophthalmology (AAO) recomenda fortemente que todos os profissionais da saúde usem Equipamentos 
de Proteção Individual que cubra a boca, o nariz e os olhos, independentemente dos sintomas do paciente. ${ }^{(18)}$ Assim, além da máscara N95, recomenda-se a utilização de óculos ou face shield. ${ }^{(19)}$ No caso dos oftalmologistas, é importante também o uso de proteção respiratória nas lâmpadas de fenda. ${ }^{(6)}$ Para evitar a propagação viral, também é recomendado o reforço das medidas higiênicas frequentes das mãos, especialmente na aplicação de colírios e para evitar o contato mão-olho, que pode ser um dos fatores de risco para congestão conjuntival em pacientes com COVID-19. ${ }^{(14)}$

\section{REFERÊNCIAS}

1. Brasil. Ministério da Saúde. Coronavírus (COVID-19). Brasília (DF): Ministério da Saúde; 2020. [citado 2020 Jun 14]. Disponível em: https:// coronavirus.saude.gov.br/

2. Ahn DG, Shin HJ, Kim MH, Lee S, Kim HS, Myoung J, et al. Current status of epidemiology, diagnosis, therapeutics, and vaccines for novel coronavirus disease 2019 (COVID-19). J Microbiol Biotechnol. 2020;30(3):313-24.

3. World Health Organization (WHO). Coronavirus disease (COVID-19) pandemic Geneve: WHO; 2021 [cited 2020 Jun 14]. Available from: https://www.who.int/emergencies/diseases/novel-coronavirus-2019

4. Brasil. Ministério da Saúde. Secretaria de Vigilância em Saúde. Boletim Epidemiológico Especial, 17: COE-COVID-19. Brasília (DF): Ministério da Saúde; 2020 [citado 2020 Jun 14]. Disponível em: http://antigo.saude.gov. br/images/pdf/2020/May/29/2020-05-25---BEE17---Boletim-do-COE.pdf

5. Seah I, Agrawal R. Can the coronavirus disease 2019 (COVID-19) affect the eyes? A review of coronaviruses and ocular implications in humans and animals. Ocul Immunol Inflamm. 2020;28(3):391-5.

6. Lauande R, Silva PJ. Coronavirus and the eye: what is relevant so far?. Arq Bras Oftalmol. 2020; 83(3):v-vi.
7. Loffredo L, Pacella F, Pacella E, Tiscione G, Oliva A, Violi F. Conjunctivitis and COVID-19: A meta-analysis. J Med Virol. 2020 Apr 24:10.1002/jmv.25938.

8. Willcox MD, Walsh K, Nichols JJ, Morgan PB, Jones LW. The ocular surface, coronaviruses and COVID-19. Clin Exp Optom. 2020;103(4):418-24.

9. Bostanci Ceran B, Ozates S. Ocular manifestations of coronavirus disease 2019. Graefes Arch Clin Exp Ophthalmol. 2020;258(9):1959-63.

10. Amesty MA, Alió Del Barrio JL, Alió JL. COVID-19 disease and ophthalmology: An update. Ophthalmol Ther. 2020;9(3):1-12.

11. Hu K, Patel J, Patel BC. Ophthalmic manifestations of coronavirus (COVID-19). StatPearls [Last Update: August 8, 2020]. Treasure Island (FL): StatPearls Publishing; 2020. [cited 2020 Jul 14]. Available from: https:// www.ncbi.nlm.nih.gov/books/NBK556093/

12. Renu K, Prasanna PL, Valsala Gopalakrishnan A. Coronaviruses pathogenesis, comorbidities and multi-organ damage - A review. Life Sci. 2020;255:117839.

13. Hong N, Yu W, Xia J, Shen Y, Yap M, Han W. Evaluation of ocular symptoms and tropism of SARS-CoV-2 in patients confirmed with COVID-19. Acta Ophthalmol. 2020 Apr 26:10.1111/aos.14445.

14. Chen L, Deng C, Chen X, Zhang X, Chen B, Yu H, et al. Ocular manifestations and clinical characteristics of 535 cases of COVID-19 in Wuhan, China: a cross-sectional study. Acta Ophthalmol. 2020 May 18:10.1111/aos.14472.

15. Navel V, Chiambaretta F, Dutheil F. Haemorrhagic conjunctivitis with pseudomembranous related to SARS-CoV-2. Am J Ophthalmol Case Rep. 2020;19:100735.

16. Ho D, Low R, Tong L, Gupta V, Veeraraghavan A, Agrawal R. COVID-19 and the ocular surface: a review of transmission and manifestations. Ocul Immunol Inflamm. 2020;28(5):726-34

17. Aiello F, Gallo Afflitto G, Mancino R, Li JO, Cesareo M, Giannini C, et al. Coronavirus disease 2019 (SARS-CoV-2) and colonization of ocular tissues and secretions: a systematic review. Eye (Lond). 2020;34(7):1206-11.

18. Chen MJ, Chang KJ, Hsu CC, Lin PY, Jui-Ling Liu C. Precaution and prevention of coronavirus disease 2019 infection in the eye. J Chin Med Assoc. 2020;83(7):648-50.

19. Ferioli M, Cisternino C, Leo V, Pisani L, Palange $P$, Nava S. Protecting healthcare workers from SARS-CoV-2 infection: practical indications. Eur Respir Rev. 2020;29(155):200068. 